\title{
Application of Dynamical and Statistical Downscaling to East Asian Summer Precipitation for Finely Resolved Datasets
}

\author{
Yoo-Bin Yhang, ${ }^{1}$ Soo-Jin Sohn, ${ }^{1}$ and Il-Won Jung ${ }^{2}$ \\ ${ }^{1}$ Climate Prediction Department, APEC Climate Center (APCC), Busan, Republic of Korea \\ ${ }^{2}$ Research Institute for Infrastructure Performance, Korea Infrastructure Safety \& Technology Corporation, Jinju, Republic of Korea \\ Correspondence should be addressed to Soo-Jin Sohn; jeenie7@apcc21.org
}

Received 21 November 2016; Accepted 15 January 2017; Published 8 February 2017

Academic Editor: Pedro Jiménez-Guerrero

Copyright (c) 2017 Yoo-Bin Yhang et al. This is an open access article distributed under the Creative Commons Attribution License, which permits unrestricted use, distribution, and reproduction in any medium, provided the original work is properly cited.

\begin{abstract}
Various downscaling approaches have been developed to overcome the limitation of the coarse spatial resolution of general circulation models (GCMs). Such techniques can be grouped into two approaches of dynamical and statistical downscaling. In this study, we investigated the performances of different downscaling methods, focusing on East Asian summer monsoon precipitation to obtain more finely resolved and value added datasets. The dynamical downscaling was conducted by the Regional Model Program (RMP) of the Global/Regional Integrated Model system (GRIMs), while the statistical downscaling was performed through coupled pattern-based simple linear regression. The dynamical downscaling resulted in a better representation of the spatial distribution and long-term trend than the GCM produced; however, it tended to overestimate precipitation over East Asia. In contrast, the application of the statistical downscaling resulted in a bias in the amount of precipitation, due to low variance that is inherent in regression-based downscaling. A combination of dynamical and statistical downscaling produced the best results in time and space. This study provides a guideline for determining the most effective and robust downscaling method in the hydrometeorological applications, which are quite sensitive to the accuracy of downscaled precipitation.
\end{abstract}

\section{Introduction}

Precipitation is the fundamental source of water to replenish stored resources such as rivers, dams, and reservoirs and for ground recharges. Therefore, it is vital to know when, where, and how much water is available at any given time for regional water resource management that strives to minimize adverse climate-related stresses in the near and distant future $[1,2]$. To achieve the sustainable water management at a certain region, the reliable precipitation forecasts with high-spatial resolution are prerequisite for managing the water supply for many reasons including domestic and agriculture use and flood protection (e.g., [3-5]).

Advanced general circulation models (GCMs) that represent physical processes and feedbacks in the atmosphere, ocean, land, and cryosphere can give credible forecasts of climate condition at least at the continental or global scale [6-10]. However, their performance of simulating regional precipitation still does not satisfy the requirements of local decision makers and practitioners [11-14]. To overcome this limitation, climate downscaling has been widely investigated in studies that have assessed the impacts of climate change [15-19] and seasonal forecasting [20-23].

In the last two decades, the applicability of dynamical downscaling has been considerably improved based on advances in computing and physics parameterizations [2428]. These studies have reported that dynamic downscaling with high-resolution models can improve the simulation of the vertical motions of storms that are driven by topography and convectional rainfall in complex terrain and consequently result in a more accurate representation of regional precipitation characteristics. A number of studies have evaluated the performance of regional climate models (RCMs) to simulate climate in East Asia $[29,30]$. However, the performance of dynamic downscaling is extremely dependent on the selection of RCMs and physics parameterization in RCMs [14]. In addition, error propagation problems, such as overcorrecting the noise of GCM simulations, can occur when RCMs regard GCM's biases as internal variability or true boundary forcing [31]. For the parameters in which 
local processes play an important role, such as precipitation or near-surface temperature, the internal variability can grow large in a RCM [32]. These weaknesses of dynamic downscaling have led to the continuous employment of statistical downscaling or bias correction prior to using dynamic downscaled information for application studies [33, 34].

Despite advances in GCM-simulated precipitation, downscaling as a postprocessing operation is necessary for application assessments at relevant spatial scales [34]. Therefore, one of major issues is which downscaling approach will provide the best spatially detailed precipitation. Therefore, this study investigated the performance of different downscaling methods focusing on East Asian summer precipitation. We first assumed that the GCM could reproduce as much accurate spatiotemporal precipitation as the real observations, and we then employed three different downscaling approaches, dynamical and statistical downscaling and a combination of both, and evaluated their performances based on the GCM as reference. This study provides a guideline for determining the most effective and robust downscaling method to use in the application studies, which are very sensitive to the accuracy of downscaled precipitation.

The remainder of this article is organized as follows: Section 2 describes the GCM, observational data, and methodology used in this study. Section 3 compares the various downscaling methods with several aspects of downscaled precipitation. Finally, Section 4 summarizes the key findings and presents conclusions of this study.

\section{Data and Methodology}

2.1. Observational Data. We assessed the performance of the Perfect GCM and various downscaling methods on the basis of the newly available gauge-based high-quality precipitation data from the Asian Precipitation-Highly Resolved Observational Data Integration Towards Evaluation of the Water Resources (APHRODITE's Water Resources) [35]. The APHRODITE v1101 is a daily gridded precipitation dataset, which is presently the only long-term, continental-scale, high-resolution daily product. The dataset covers a period of more than 57 years for monsoon Asia, the Middle East, and northern Eurasia. It is available on $0.5^{\circ} \times 0.5^{\circ}$ and $0.25^{\circ} \times$ $0.25^{\circ}$ grid meshes. It was created by collecting and analyzing rain gauge observations from 5,000 to 12,000 stations across Asia through the APHRODITE project, which represents 2.3 to 4.5 times the data made available through the Global Telecommunication System (GTS) network. In this study, we used $0.25^{\circ} \times 0.25^{\circ}$ gridded data.

2.2. Perfect GCM. As mentioned in Section 1, state-of-theart climate models are still incomplete due to their coarse resolutions, despite the fact that most extreme hydrological droughts and floods happen on subgrid scales. Such regional climate information can be obtained from coarsescale GCM products by employing dynamical and statistical downscaling. In this study, the National Centers for
Environmental Prediction-Department of Energy (NCEPDOE) Atmospheric Model Intercomparison Project (AMIPII) reanalysis (R2) [36] was adopted as "Perfect GCM" to avoid any other model problems such as inherent low predictability over mid-to-high latitudes, uncertainties in initial values, and parameterization of unresolved subgrid scale process. Note that the precipitation product from NCEPDOE reanalysis is model output and strongly depends on the model physics. The data uses $2.5^{\circ} \times 2.5^{\circ}$ latitude-longitude global grid system. This GCM outputs are used in dynamical downscaling as initial and lateral boundary conditions and statistical downscaling as predictor.

2.3. Dynamical Downscaling. Dynamical downscaling is conducted by the Regional Model Program (RMP) of the Global/Regional Integrated Model system (GRIMs) [37]. Since the GRIMs has been originally designed for multipurpose such as weather prediction and seasonal forecasting, it could be characterized by multiscale integration covering global to regional climate and unified physics. The physics schemes used in this study is the version 3.2 for GRIMs physics package, which consists of Hong and Pan [38] for deep convection, Hong et al. [39] for cloud microphysics, Chou et al. [40] for longwave radiation, Chou [41] for shortwave radiation, Hong et al. [42] for vertical diffusion physical parameterization, and the National Centers for Environmental Prediction (NCEP), Oregon State University, US Air Force, National Weather Service Office of Hydrologic Development (NOAH) land surface model $[43,44]$. It has been demonstrated that the GRIMs-RMP could be a better tool to understand the Asian monsoon precipitation mechanism [45, 46].

2.4. Statistical Downscaling. The products from the Perfect GCM and dynamical downscaling can be statistically downscaled based on the coupled pattern selection and projection [47]. Coupled patterns represent the relationship between local precipitation and the variation of large-scale pattern. The pattern projection is thus based on the premise that the large-scale pattern can be well simulated by dynamical models and that local precipitation forecasts may be retrieved from the information in the coupled pattern as a proper transfer function. The coupled pattern is selected by scanning a moving window over the globe (for Perfect GCM) and the domain of dynamical downscaling. The optimal window of coupled pattern is defined by the area in which the correlation value between predictand and predictor is the highest. The $850 \mathrm{hPa}$ wind components from Perfect GCM and precipitation from dynamical downscaling results are used as predictors for statistical downscaling.

2.5. Experimental Design. The performance of various downscaling methods was evaluated by comparing the results of several downscaling-based experiments. Figure 1 shows the schematic diagram representing the adopted methods of data processing. First of all, the difference in performance between dynamical (hereafter "DYN") and statistical ("STA") downscalings obtained by directly using outputs of 


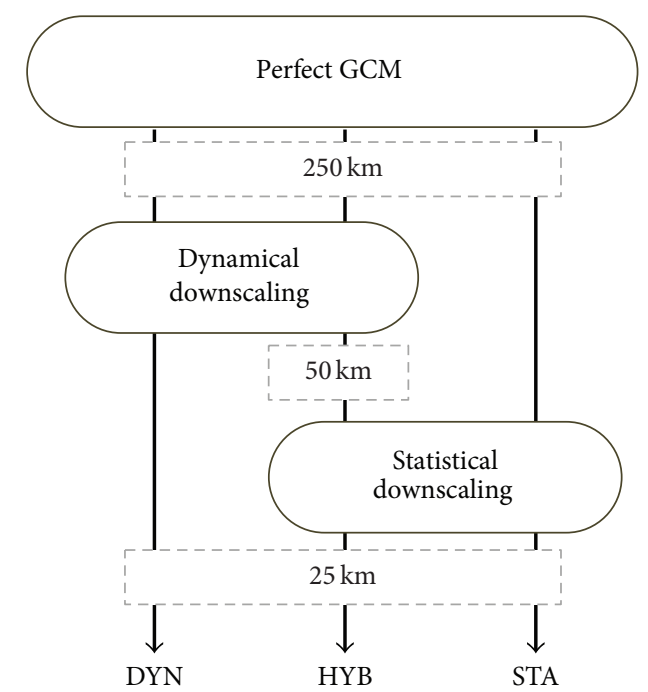

FIgURE 1: Experimental design used in this study.

the Perfect GCM was studied. The other experiment was a hybrid dynamical-statistical downscaling method, in which the precipitation data with $25 \mathrm{~km}$ resolution was obtained by statistically downscaling the precipitation products from dynamically downscaled precipitation with $50 \mathrm{~km}$ resolution as predictor ("HYB"). The common analysis domains for all experiments were $113^{\circ}-142 \mathrm{E}^{\circ}$ and $23^{\circ}-46 \mathrm{~N}^{\circ}$. Three downscaling experiments are conducted for 29 summers (June-JulyAugust) from 1979 to 2007.

\section{Results}

Figure 2 shows the 29-summer mean precipitation from the observations, the Prefect GCM, and the three downscaling experiments. Due to coarse resolution, the GCM data could not reproduce local maxima in Japanese Archipelago and South Korea (Figures 2(a) and 2(b)). In addition, precipitation was overestimated in southeastern China and Manchuria. It implies that GCM could not resolve mesoscale phenomena such as precipitation because many important topographic features were missing. For example, the land/sea was approximated and the geographical shape of the Korean peninsula and Japan could not be conveniently captured at the adopted resolution. The dynamically downscaled field, with a $25 \mathrm{~km}$ horizontal resolution, represented a finer distribution of precipitation than the GCM. Although the DYN tended to overestimate the amount of rainfall over the land, the overall regional patterns of precipitation were well reproduced (Figure 2(c)). Statistically downscaled precipitation from the Perfect GCM simulated a similar rainfall distribution to that of observation (Figure 2(d)). The hybrid dynamical-statistical approach produced a very similar spatial pattern to the observation with spatial correlation of 0.99 (Figure 2(e)).

In terms of the spatial correlations between the observed and downscaled seasonal mean precipitation, the STA generally had a higher correlation than the DYN except for
1991, 1994, and 1999 (Figure 3(a)). It was mainly due to the overestimated precipitation in the DYN (Figure 3(b)). While statistical downscaling represented the climatological rainfall amount and its spatial distribution well, dynamical downscaling followed the observed interannual variation (Figure 3(b)). However, the DYN exceeded the observed amount, which was due to error propagation from GCM to RCM (see Introduction). The spatial correlation of the HYB was superior to that of the STA during the 29 summers (Figure 3(a)). In addition, the hybrid dynamical-statistical approach reduced the wet biases shown in the DYN (Figure $3(\mathrm{~b})$ ). Compared to the STA (i.e., the application of the statistical downscaling only), the HYB can improve the reproduction of year-to-year variation and was closer to the observation. The temporal correlation of the HYB was improved to 0.71 (from 0.1 for the STA).

Figure 4 is a box plot of the observed precipitation and the precipitation simulated by various experiments during the 29 summers. Box plots are generally used to illustrate the dataset's statistics with a wide range of variation [48]. The box represents the interquartile range and contains $50 \%$ of the data; the upper edge of the box represents the 75th percentile, while the lower edge is the 25th percentile. The horizontal lines within the box are the median. The whiskers extend out to 1.5 times the interquartile range of the data. Values beyond those points are identified as outliers and marked in closed circle. There were overestimations in the total precipitation amount simulated by the GCM and DYN (consistent with previous results). The median of the STA and HYB was close to that of observation. The variance of the STA was too low to reproduce the interannual variability shown in the observation, while the DYN simulated excessive precipitation than the observed amount. The combination of the DYN and STA resulted in improved performance.

To compare the performance of the simulations in reproducing the anomalous characteristics for wet and dry summers, a composite analysis was undertaken in Figure 5. Based on the observed precipitation anomaly (see Figure 2(b)), we categorized six wet summers in 1993, 1995, 1996, 1998, 1999, and 2006 and five dry summers in 1981, 1986, 1988, 1989, and 1992. Rainfall maxima were observed over monsoonal rain bands extending from the northeast of south China to the south of Japan in both in wet and dry years (Figure 5(a)). The patterns of precipitation in the GCM were much smoother than the observation due to a coarser resolution (Figure 5(b)). The GCM produced excessive precipitation over south China but less over South Korea and Japan. The DYN tended to overestimate precipitation over East Asia in both wet and dry years, which resulted in much wetter simulated conditions than in the observations (Figure 5(c)). Compared to observations, the STA produced less precipitation in the wet years but more precipitation in the dry years (Figure 5(d)). This resulted in drier conditions in the composite difference. The HYB simulated similar rainfall distribution to the STA; however, it was much closer to the observations (Figure 5(e)). For example, the rainfall maxima over south China and the Korean Peninsula in wet years had similar spatial patterns and rainfall amount to the observations. 


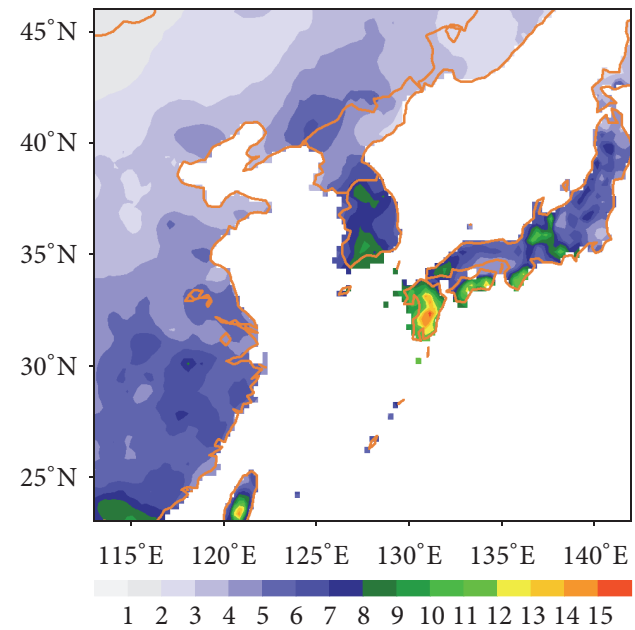

(a) OBS

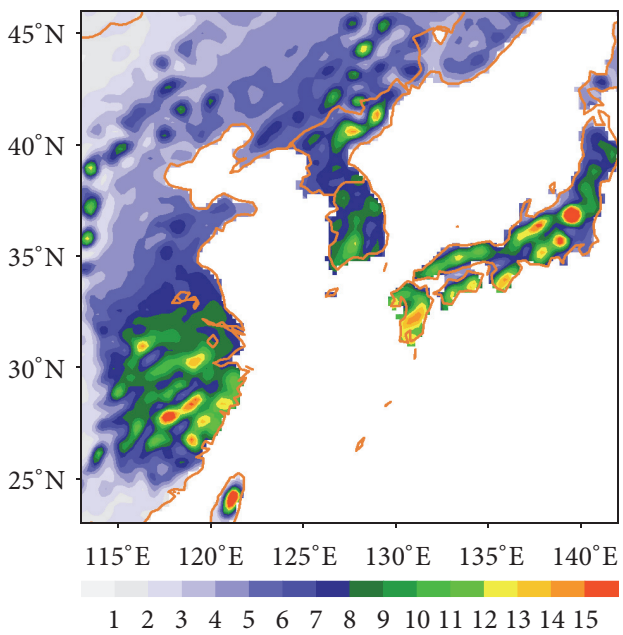

(c) DYN

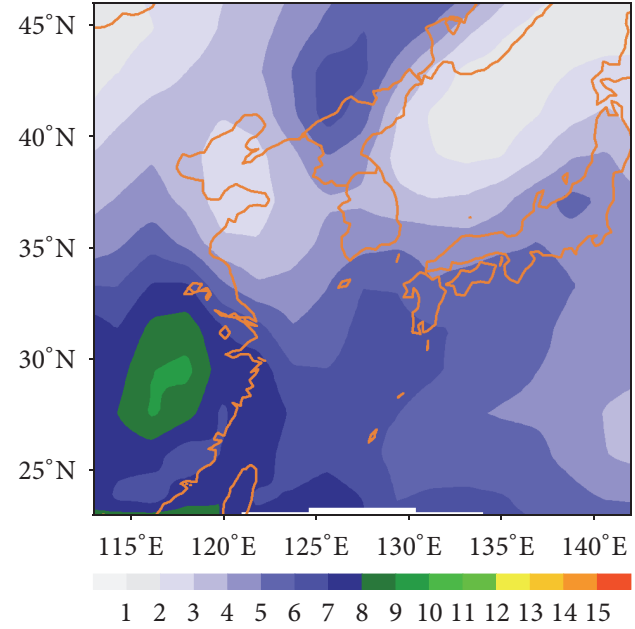

(b) GCM

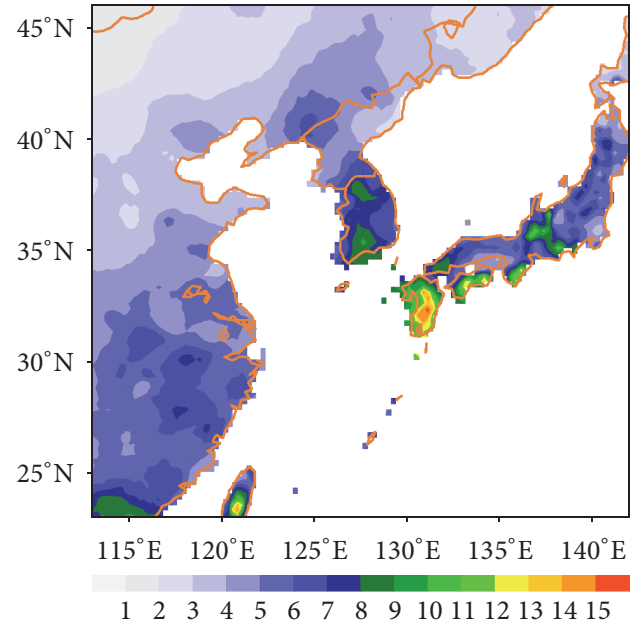

(d) STA

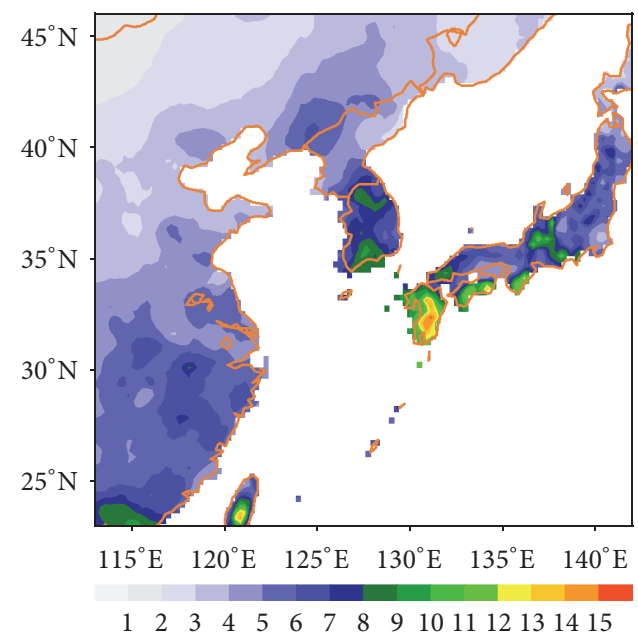

(e) HYB

Figure 2: The 29-summer mean precipitation (mm/day) of (a) observation, (b) Perfect general circulation model (GCM), (c) dynamical downscaling (DYN), (d) statistical downscaling (STA), and (e) hybrid dynamical-statistical downscaling (HYB). 


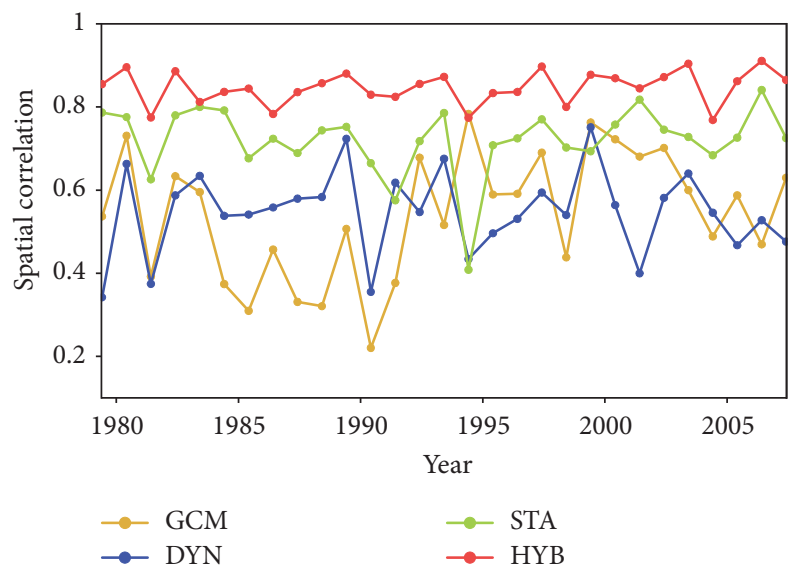

(a) Spatial correlation

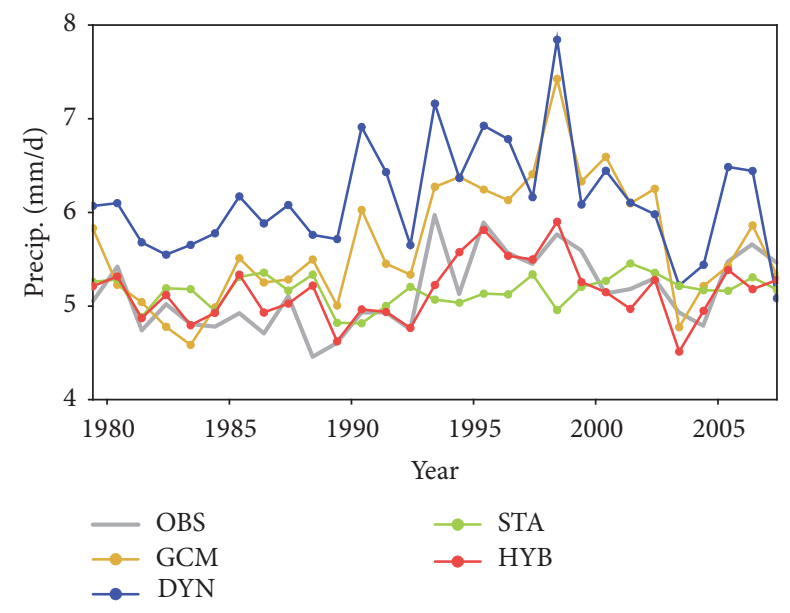

(b) Amount

FIGURE 3: Time series of the (a) spatial correlation and (b) amount $\left(\mathrm{mm} /\right.$ day) averaged over East Asia $\left(113^{\circ}-142 \mathrm{E}^{\circ}, 23^{\circ}-46 \mathrm{~N}^{\circ}\right)$ from 1979 to 2007 summer.

Finally, we investigated how well the temporal variation of experimental results matches the observations in individual subregions in terms of the correlation, root meansquare error (RMSE), and the ratio of variance. The results are summarized as Taylor diagram in Figure 6 [49]. The analyzed domain was divided into four subregions: South Korea $\left(125^{\circ} \mathrm{E}-130^{\circ} \mathrm{E}, 33^{\circ} \mathrm{N}-38^{\circ} \mathrm{N}\right)$, northern China $\left(113^{\circ} \mathrm{E}-\right.$ $131^{\circ} \mathrm{E}, 40^{\circ} \mathrm{N}-46^{\circ} \mathrm{N}$,), southern China $\left(113^{\circ} \mathrm{E}-123^{\circ} \mathrm{E}, 23^{\circ} \mathrm{N}-\right.$ $\left.38^{\circ} \mathrm{N}\right)$, and Japanese Archipelago $\left(131^{\circ} \mathrm{E}-141^{\circ} \mathrm{E}, 30^{\circ} \mathrm{N}-42^{\circ} \mathrm{N}\right)$. The standard deviations of the observed precipitation in South Korea, northern China, southern China, and Japan were $2.15,0.82,1.54$, and 2.26, respectively. Normalized standard deviations of the GCM, DYN, STA, and HYB were represented by ratios to the OBS. The DYN tended to simulate higher values than the other experiments. In particular, the amount of precipitation over the in-land area of China simulated by RCM (orange and red, number 2) was more exaggerated than in the GCM (number 1). It implies that the bias of GCM can occasionally be amplified in the RCM, but not by simply transferring the bias. The application of a statistical downscaling caused a reduction in variation, which

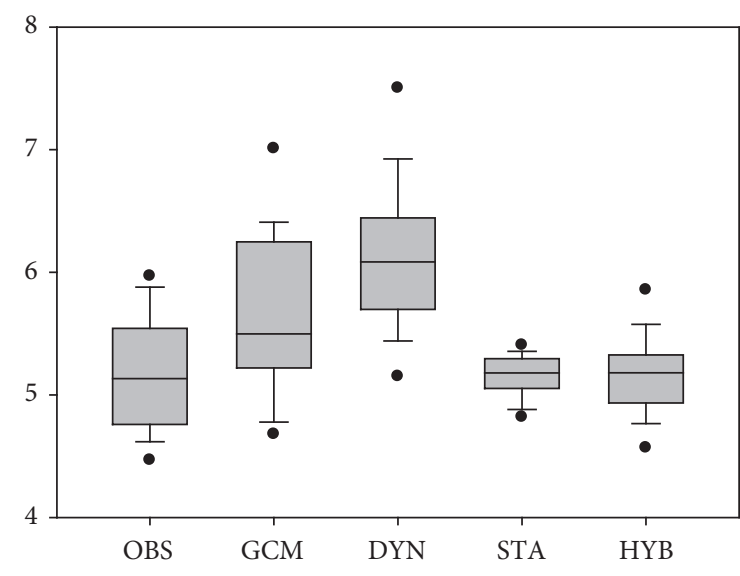

Figure 4: Box plot of precipitation for 29 summers.

results in lower standard deviation of the STA and HYB. The correlation for the STA was lower due to its smaller variance in subregions. The GCM, DYN, and HYB had higher correlations, with the value over 0.6. The HYB had the best performance for simulating the temporal variation and RMSE of precipitation in south China and north China.

\section{Concluding Remarks}

Precise and finely resolved climate information is needed for hydrological applications, such as water resource management. Although there is the Perfect GCM output available, downscaled information is much more useful than the direct output of the GCM results due to the scale issue. Simply interpolating or downscaling coarse to fine resolution data cannot guarantee the better results. Therefore, a welldesigned and well-validated downscaling strategy is very important. In this study, two typical downscaling methods for East Asian summer precipitation prediction were assessed. Both the DYN and STA produced a better representation of the regional precipitation distribution over East Asia than the GCM. However, the DYN has a limitation in simulating the amount of precipitation over time and tends to overestimate it particularly for major East Asia summer monsoon region, southeast China, Korean Peninsula, and Japanese Archipelago. It is widely known that most dynamical models are suffering from the exaggeration of rainfall amounts over land $[50,51]$. In contrast, the STA had smaller interannual variability than the observations. The STA adopted in this study is regression-based downscaling method, which brings low variance [52]. A new hybrid dynamical-statistical downscaling method was thus applied. The combined downscaling approach produced the best results in time and space. In particular, the HYB was better at detecting extreme cases, wet and dry summer monsoon years, and reproducing regional rainfall distribution over southern and northern China, South Korea, and Japan.

The results presented indicate the relative role of each downscaling method. It is well known that the dynamical downscaling captures regional forcings such as complex orography and land-sea contrast and produces physically 


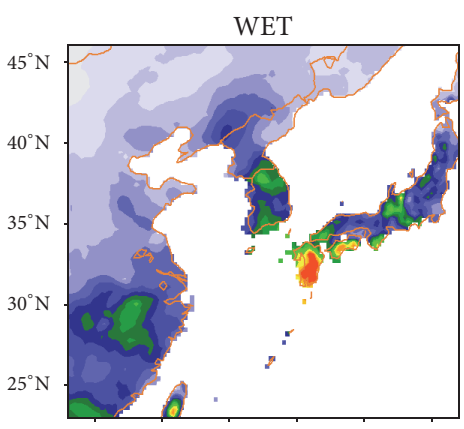

$115^{\circ} \mathrm{E} \quad 120^{\circ} \mathrm{E} \quad 125^{\circ} \mathrm{E} \quad 130^{\circ} \mathrm{E} \quad 135^{\circ} \mathrm{E} \quad 140^{\circ} \mathrm{E}$

1223045067889101112131415

WET

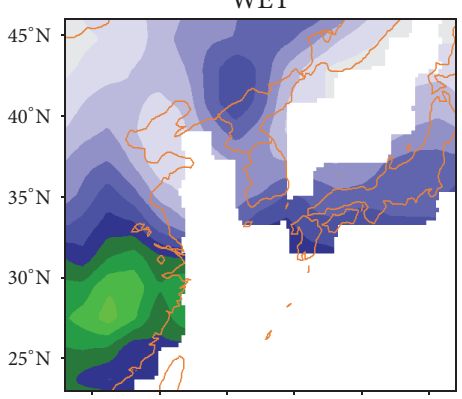

$115^{\circ} \mathrm{E} \quad 120^{\circ} \mathrm{E} \quad 125^{\circ} \mathrm{E} \quad 130^{\circ} \mathrm{E} \quad 135^{\circ} \mathrm{E} \quad 140^{\circ} \mathrm{E}$

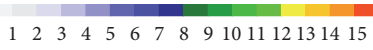

WET

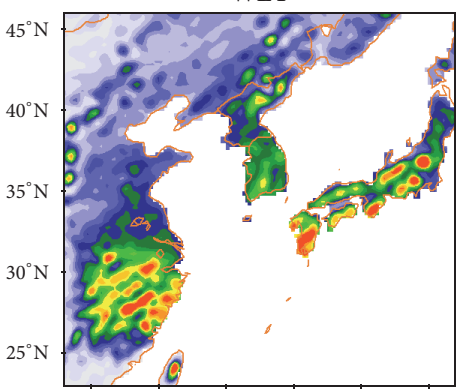

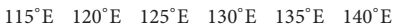

1223445677899101112131415

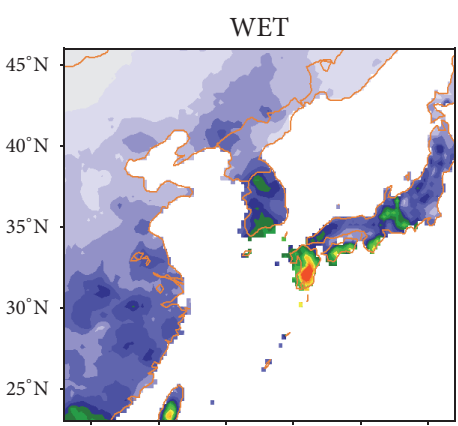

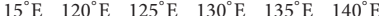

$\begin{array}{llllllllll}1 & 2 & 3 & 4 & 5 & 6 & 7 & 8 & 9 & 101112131415\end{array}$

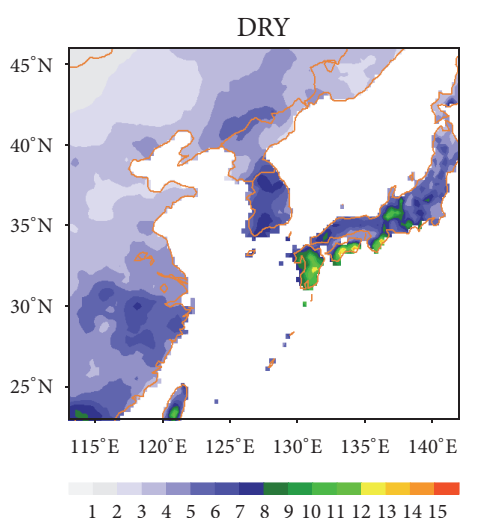

(a) OBS

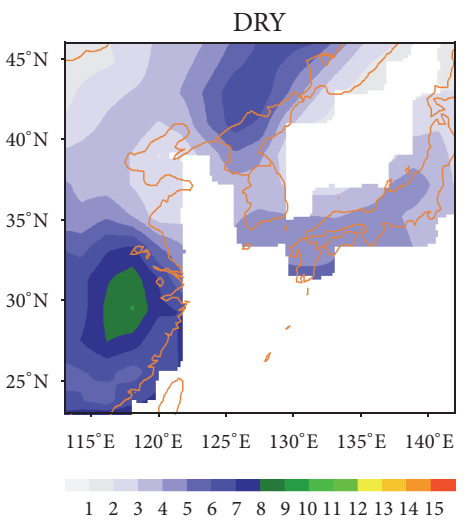

(b) GCM

DRY

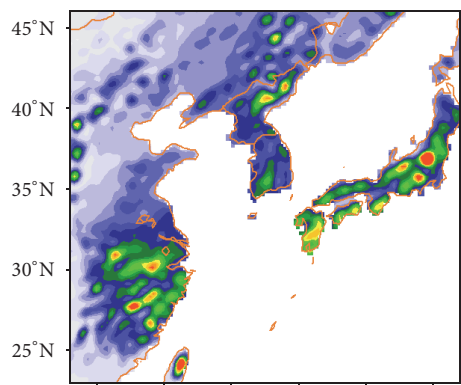

$115^{\circ} \mathrm{E} \quad 120^{\circ} \mathrm{E} \quad 125^{\circ} \mathrm{E} \quad 130^{\circ} \mathrm{E} \quad 135^{\circ} \mathrm{E} \quad 140^{\circ} \mathrm{E}$

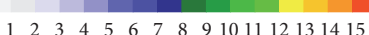

(c) DYN

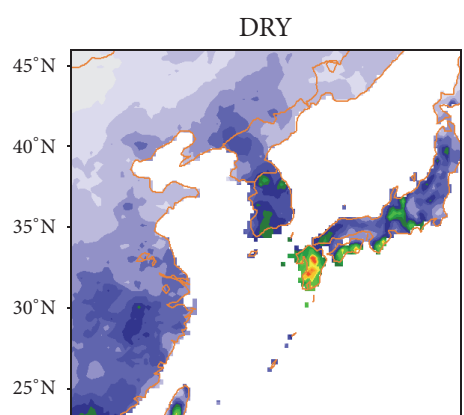

$115^{\circ} \mathrm{E} \quad 120^{\circ} \mathrm{E} \quad 125^{\circ} \mathrm{E} \quad 130^{\circ} \mathrm{E} \quad 135^{\circ} \mathrm{E} \quad 140^{\circ} \mathrm{E}$

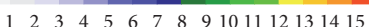

(d) STA
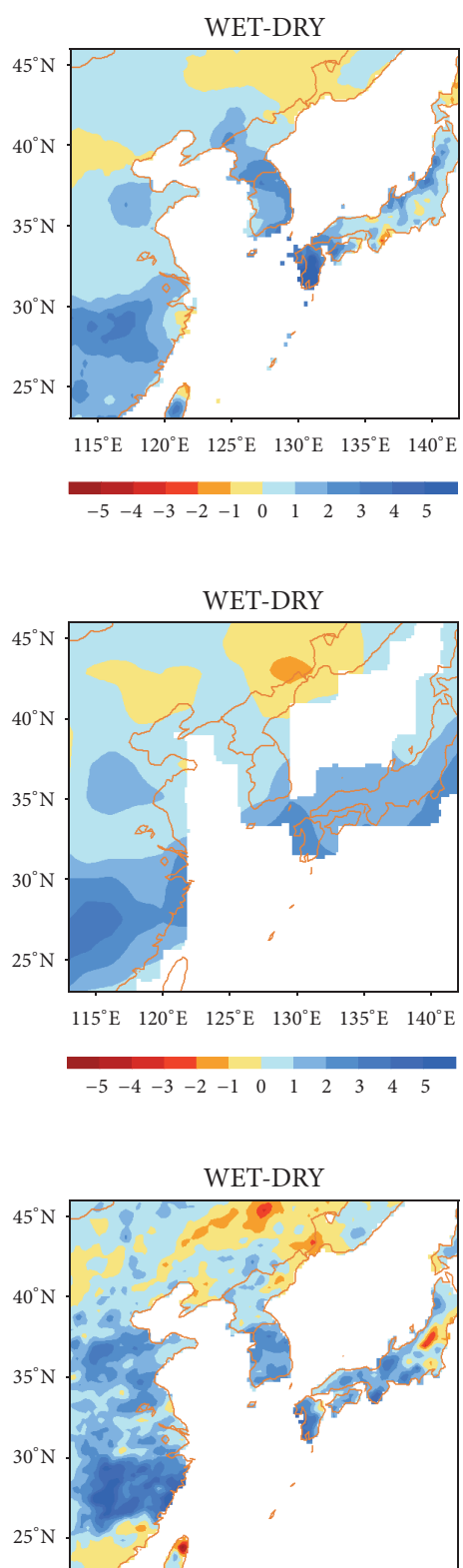

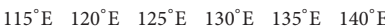
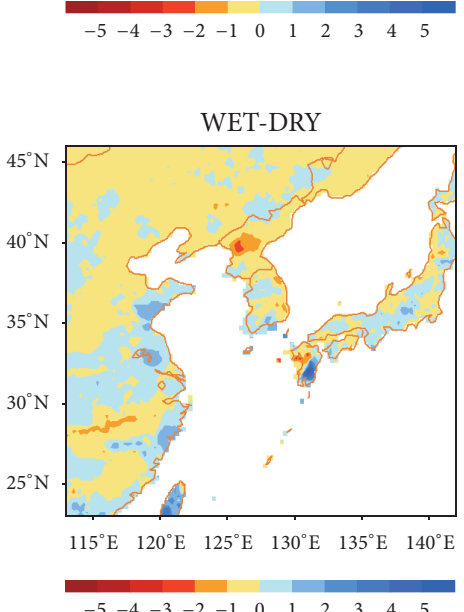

Figure 5: Continued. 

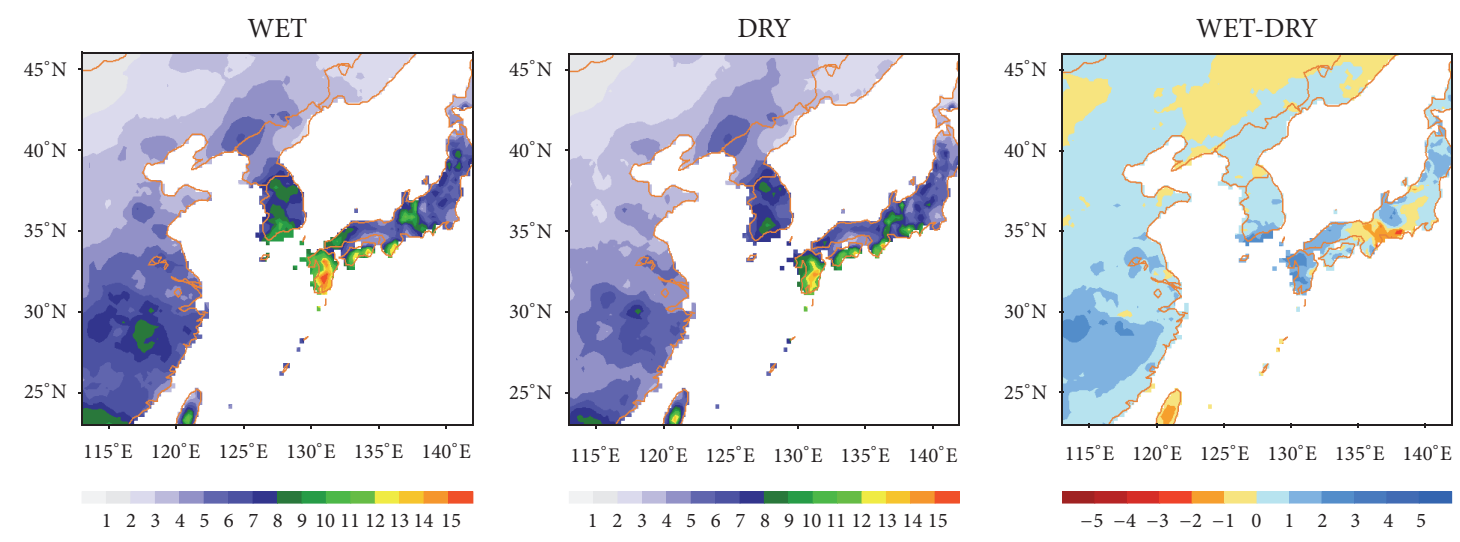

(e) HYB

FIGURE 5: Composite precipitation for wet years, dry years, and difference between wet and dry years of the (a) observation, (b) GCM, (c) DYN, (d) STA, and (e) HYB.

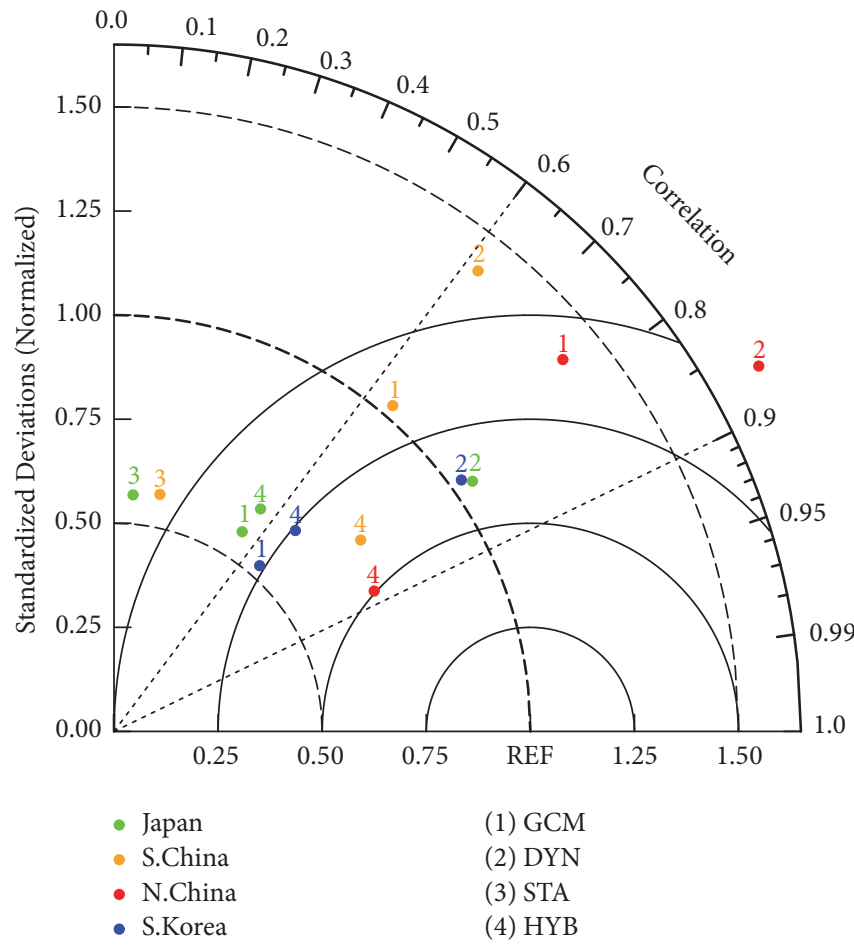

Figure 6: Taylor diagram for precipitation of the observation, GCM, DYN, STA, and HYB for subregions (South Korea: $125^{\circ} \mathrm{E}-130^{\circ} \mathrm{E}, 33^{\circ} \mathrm{N}-$ $38^{\circ} \mathrm{N}$, northern China: $113^{\circ} \mathrm{E}-131^{\circ} \mathrm{E}, 40^{\circ} \mathrm{N}-46^{\circ} \mathrm{N}$, southern China: $113^{\circ} \mathrm{E}-123^{\circ} \mathrm{E}, 23^{\circ} \mathrm{N}-38^{\circ} \mathrm{N}$, and Japan: $131^{\circ} \mathrm{E}-141^{\circ} \mathrm{E}, 30^{\circ} \mathrm{N}-42^{\circ} \mathrm{N}$ ).

coherent patterns in the tendency of key impact indicators. This is a desired characteristic for the generation of usable climate information [53]. Although a dynamical downscaling is not sufficient for improving the quality of climate information, it does appear to be a necessary precondition for the generation of climate information when local dynamics and feedbacks are poorly represented in a GCM. Then the statistical downscaling may be employed as a further correction of existing residual bias, which implies the statistical downscaling can be considered a practical tool for removing the systematic bias of a model.
There were some uncertainties and limitations in this study. First, since we used a single GCM, a single RCM, and a single statistical downscaling, the models must have any inherent uncertainties and intrinsic limitations. This can be generally overcome through the use of several models, and it should be considered in further study. To efficiently assess and better contextualize the results obtained from this study, the uncertainties could be disregarded. Second, we use the Perfect GCM (i.e., reanalysis dataset), which allowed us to ignore the systematic bias and low predictability generated by a GCM. The real GCM output should be employed in 
real seasonal forecasting and the relevant impact needs to be explored in future.

\section{Competing Interests}

The authors declare that there is no conflict of interests regarding the publication of this paper.

\section{Acknowledgments}

This research was supported by the APEC Climate Center. The APEC Climate Center operations are supported by KREONET (Korea Research Environment Open NETwork) which is managed and operated by KISTI (Korea Institute of Science and Technology Information).

\section{References}

[1] N. Devineni, U. Lall, E. Etienne, D. Shi, and C. Xi, "America's water risk: current demand and climate variability," Geophysical Research Letters, vol. 42, no. 7, pp. 2285-2293, 2015.

[2] W. J. Cosgrove and D. P. Loucks, "Water management: current and future challenges and research directions," Water Resources Research, vol. 51, no. 6, pp. 4823-4839, 2015.

[3] K. Strzepek, M. Jacobsen, B. Boehlert, and J. Neumann, “Toward evaluating the effect of climate change on investments in the water resources sector: insights from the forecast and analysis of hydrological indicators in developing countries," Environmental Research Letters, vol. 8, no. 4, Article ID 044014, 2013.

[4] W. Li, A. Sankarasubramanian, R. S. Ranjithan, and E. D. Brill, "Improved regional water management utilizing climate forecasts: An interbasin transfer model with a risk management framework," Water Resources Research, vol. 50, no. 8, pp. 68106827, 2014.

[5] D. Anghileri, N. Voisin, A. Castelletti, F. Pianosi, B. Nijssen, and D. P. Lettenmaier, "Value of long-term streamflow forecasts to reservoir operations for water supply in snow-dominated river catchments," Water Resources Research, vol. 52, no. 6, pp. 42094225, 2016.

[6] C. Gulizia and I. Camilloni, "Comparative analysis of the ability of a set of CMIP3 and CMIP5 global climate models to represent precipitation in South America," International Journal of Climatology, vol. 35, no. 4, pp. 583-595, 2015.

[7] A. Nair, U. C. Mohanty, and T. C. Panda, "Improving the performance of precipitation outputs from Global Climate Models to predict monthly and seasonal rainfall over the Indian subcontinent," Comptes Rendus Geoscience, vol. 347, no. 2, pp. 53-63, 2015.

[8] J. Perez, M. Menendez, F. J. Mendez, and I. J. Losada, “Evaluating the performance of CMIP3 and CMIP5 global climate models over the north-east Atlantic region," Climate Dynamics, vol. 43, no. 9, pp. 2663-2680, 2014.

[9] J. Ramirez-Villegas, A. J. Challinor, P. K. Thornton, and A. Jarvis, "Implications of regional improvement in global climate models for agricultural impact research," Environmental Research Letters, vol. 8, no. 2, Article ID 024018, 2013.

[10] F. Su, X. Duan, D. Chen, Z. Hao, and L. Cuo, "Evaluation of the global climate models in the CMIP5 over the Tibetan Plateau," Journal of Climate, vol. 26, no. 10, pp. 3187-3208, 2013.

[11] J. Schmidli, C. Frei, and P. L. Vidale, "Downscaling from GCM precipitation: a benchmark for dynamical and statistical downscaling methods," International Journal of Climatology, vol. 26, no. 5, pp. 679-689, 2006.

[12] D. Jacob, L. Bärring, O. B. Christensen et al., "An intercomparison of regional climate models for Europe: model performance in present-day climate," Climatic Change, vol. 81, no. 1, pp. 31-52, 2007.

[13] D. Maraun, F. Wetterhall, A. M. Ireson et al., "Precipitation downscaling under climate change: recent developments to bridge the gap between dynamical models and the end user," Reviews of Geophysics, vol. 48, no. 3, 2010.

[14] L. O. Mearns, S. Sain, L. R. Leung et al., "Climate change projections of the North American Regional Climate Change Assessment Program (NARCCAP)," Climatic Change, vol. 120, no. 4, pp. 965-975, 2013.

[15] H. J. Fowler, S. Blenkinsop, and C. Tebaldi, "Linking climate change modelling to impacts studies: recent advances in downscaling techniques for hydrological modelling," International Journal of Climatology, vol. 27, no. 12, pp. 1547-1578, 2007.

[16] E. P. Salathé Jr., P. W. Mote, and M. W. Wiley, "Review of scenario selection and downscaling methods for the assessment of climate change impacts on hydrology in the United States Pacific Northwest," International Journal of Climatology, vol. 27, no. 12, pp. 1611-1621, 2007.

[17] N. Bhuvandas, P. V. Timbadiya, P. L. Patel, and P. D. Porey, "Review of downscaling methods in climate change and their role in hydrological studies," World Academy of Science, Engineering and Technology, vol. 8, pp. 660-665, 2014.

[18] Y. Xue, Z. Janjic, J. Dudhia, R. Vasic, and F. De Sales, "A review on regional dynamical downscaling in intraseasonal to seasonal simulation/prediction and major factors that affect downscaling ability," Atmospheric Research, vol. 147-148, pp. 68-85, 2014.

[19] E. G. Bi, P. Gachon, M. Vrac, and F. Monette, "Which downscaled rainfall data for climate change impact studies in urban areas? Review of current approaches and trends," Theoretical and Applied Climatology, vol. 127, no. 3, pp. 685-699, 2017.

[20] Y.-M. Min, V. N. Kryjov, and J.-H. Oh, "Probabilistic interpretation of regression-based downscaled seasonal ensemble predictions with the estimation of uncertainty," Journal of Geophysical Research Atmospheres, vol. 116, no. 8, Article ID D08101, 2011.

[21] S.-J. Sohn, J.-B. Ahn, and C.-Y. Tam, "Six month-lead downscaling prediction of winter to spring drought in South Korea based on a multimodel ensemble," Geophysical Research Letters, vol. 40, no. 3, pp. 579-583, 2013.

[22] X. Yuan, E. F. Wood, J. K. Roundy, and M. Pan, "CFSv2-Based seasonal hydroclimatic forecasts over the conterminous United States," Journal of Climate, vol. 26, no. 13, pp. 4828-4847, 2013.

[23] S. Kang, J. Hur, and J.-B. Ahn, "Statistical downscaling methods based on APCC multi-model ensemble for seasonal prediction over South Korea," International Journal of Climatology, vol. 34, no. 14, pp. 3801-3810, 2014.

[24] M. L. Weisman, W. C. Skamarock, and J. B. Klemp, "The resolution dependence of explicitly modeled convective systems," Monthly Weather Review, vol. 125, no. 4, pp. 527-548, 1997.

[25] W. C. Skamarock, J. B. Klemp, J. Dudhia et al., A Description of the Advanced Research WRF Version 2, (No. NCAR/TN-468+ STR), National Center for Atmospheric Research, Mesoscale and Microscale Meteorology Division, Boulder, Colo, USA, 2005.

[26] K. Ikeda, R. Rasmussen, C. Liu et al., "Simulation of seasonal snowfall over Colorado," Atmospheric Research, vol. 97, no. 4, pp. 462-477, 2010. 
[27] R. Rasmussen, C. Liu, K. Ikeda et al., "High-resolution coupled climate runoff simulations of seasonal snowfall over Colorado: a process study of current and warmer climate," Journal of Climate, vol. 24, no. 12, pp. 3015-3048, 2011.

[28] R. Rasmussen, K. Ikeda, C. Liu et al., "Climate change impacts on the water balance of the Colorado headwaters: high-resolution regional climate model simulations," Journal of Hydrometeorology, vol. 15, no. 3, pp. 1091-1116, 2014.

[29] S.-G. Oh, M.-S. Suh, and D.-H. Cha, "Impact of lateral boundary conditions on precipitation and temperature extremes over South Korea in the CORDEX regional climate simulation using RegCM4," Asia-Pacific Journal of Atmospheric Sciences, vol. 49, no. 4, pp. 497-509, 2013.

[30] C. Park, S.-K. Min, D. Lee et al., "Evaluation of multiple regional climate models for summer climate extremes over East Asia," Climate Dynamics, vol. 46, no. 7, pp. 2469-2486, 2016.

[31] M. P. Clark, R. L. Wilby, E. D. Gutmann et al., "Characterizing uncertainty of the hydrologic impacts of climate change," Current Climate Change Reports, vol. 2, no. 2, pp. 55-64, 2016.

[32] K. Sieck and D. Jacob, "Influence of the boundary forcing on the internal variability of a regional climate model," American Journal of Climate Change, vol. 5, no. 3, pp. 373-382, 2016.

[33] A. W. Wood, L. R. Leung, V. Sridhar, and D. P. Lettenmaier, "Hydrologic implications of dynamical and statistical approaches to downscaling climate model outputs," Climatic Change, vol. 62, no. 1-3, pp. 189-216, 2004.

[34] T. Lafon, S. Dadson, G. Buys, and C. Prudhomme, "Bias correction of daily precipitation simulated by a regional climate model: a comparison of methods," International Journal of Climatology, vol. 33, no. 6, pp. 1367-1381, 2013.

[35] A. Yatagai, K. Kamiguchi, O. Arakawa, A. Hamada, N. Yasutomi, and A. Kitoh, "APHRODITE: constructing a long-term daily gridded precipitation dataset for Asia based on a dense network of rain gauges," Bulletin of the American Meteorological Society, vol. 93, no. 9, pp. 1401-1415, 2012.

[36] M. Kanamitsu, W. Ebiszaki, J. Wollen et al., "NCEP-DOE AMIPII Reanalysis (R-2)," Bulletin of the American Meteorological Society, vol. 83, pp. 1631-1643, 2002.

[37] S.-Y. Hong, H. Park, H.-B. Cheong et al., "The global/regional integrated model system (GRIMs)," Asia-Pacific Journal of Atmospheric Sciences, vol. 49, no. 2, pp. 219-243, 2013.

[38] S.-Y. Hong and H.-L. Pan, "Convective trigger function for a mass-flux cumulus parameterization scheme," Monthly Weather Review, vol. 126, no. 10, pp. 2599-2620, 1998.

[39] S.-Y. Hong, H.-M. H. Juang, and Q. Zhao, "Implementation of prognostic cloud scheme for a regional spectral model," Monthly Weather Review, vol. 126, no. 10, pp. 2621-2639, 1998.

[40] M.-D. Chou, K.-T. Lee, S.-C. Tsay, and Q. Fu, "Parameterization for cloud longwave scattering for use in atmospheric models," Journal of Climate, vol. 12, no. 1, pp. 159-169, 1999.

[41] M. D. Chou, "A solar radiation model for use in climate studies," Journal of the Atmospheric Sciences, vol. 49, no. 9, pp. 762-772, 1992.

[42] S.-Y. Hong, Y. Noh, and J. Dudhia, "A new vertical diffusion package with an explicit treatment of entrainment processes," Monthly Weather Review, vol. 134, no. 9, pp. 2318-2341, 2006.

[43] F. Chen and J. Dudhia, "Coupling and advanced land surfacehydrology model with the Penn State-NCAR MM5 modeling system. Part I: model implementation and sensitivity;" Monthly Weather Review, vol. 129, no. 4, pp. 569-585, 2001.
[44] M. B. Ek, K. E. Mitchell, Y. Lin et al., "Implementation of Noah land surface model advances in the National Centers for Environmental Prediction operational mesoscale Eta model," Journal of Geophysical Research D: Atmospheres, vol. 108, no. 22, pp. 1-16, 2003.

[45] S.-Y. Hong and Y.-B. Yhang, "Implications of a decadal climate shift over East Asia in winter: a modeling study," Journal of Climate, vol. 23, no. 18, pp. 4989-5001, 2010.

[46] S.-Y. Hong, M. Kanamitsu, J.-E. Kim, and M.-S. Koo, "Effects of diurnal cycle on a simulated Asian summer monsoon," Journal of Climate, vol. 25, no. 24, pp. 8394-8480, 2012.

[47] H. Kang, C.-K. Park, S. N. Hameed, and K. Ashok, "Statistical downscaling of precipitation in Korea using multimodel output variables as predictors," Monthly Weather Review, vol. 137, no. 6, pp. 1928-1938, 2009.

[48] D. S. Wilks, Statistical Methods in the Atmospheric Sciences, Academic Press, Oxford, UK, 3rd edition, 2011.

[49] K. E. Taylor, "Summarizing multiple aspects of model performance in a single diagram," Journal of Geophysical Research Atmospheres, vol. 106, no. 7, pp. 7183-7192, 2001.

[50] Y.-B. Yhang and S.-Y. Hong, "A simulated climatology of the East Asian summer monsoon using a regional spectral model," Asia-Pacific Journal of Atmospheric Sciences, vol. 44, no. 4, pp. 325-339, 2008.

[51] J.-H. Park, S.-G. Oh, and M.-S. Suh, "Impacts of boundary conditions on the precipitation simulation of RegCM4 in the CORDEX East Asia domain," Journal of Geophysical Research Atmospheres, vol. 118, no. 4, pp. 1652-1667, 2013.

[52] S.-J. Sohn, C.-Y. Tam, and J.-B. Ahn, "Development of a multimodel-based seasonal prediction system for extreme droughts and floods: a case study for South Korea," International Journal of Climatology, vol. 33, no. 4, pp. 793-805, 2013.

[53] A. Dell'Aquila, S. Calmanti, P. Ruti et al., "Effects of seasonal cycle fluctuations in an A1B scenario over the EuroMediterranean region," Climate Research, vol. 52, no. 1, pp. 135157, 2012. 

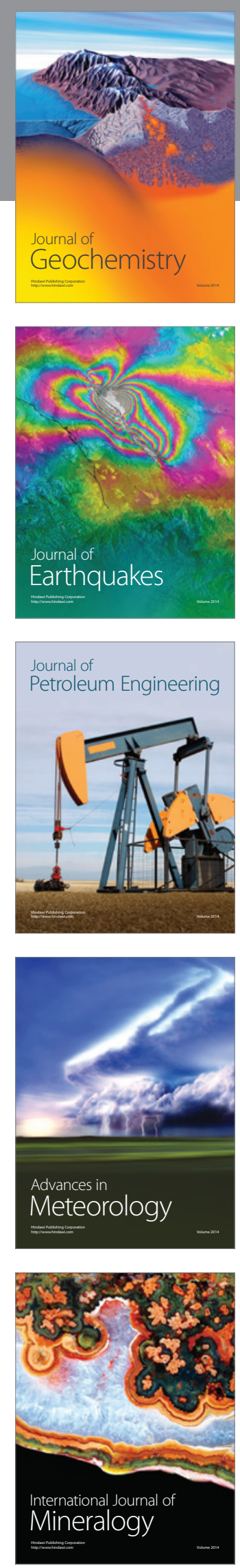
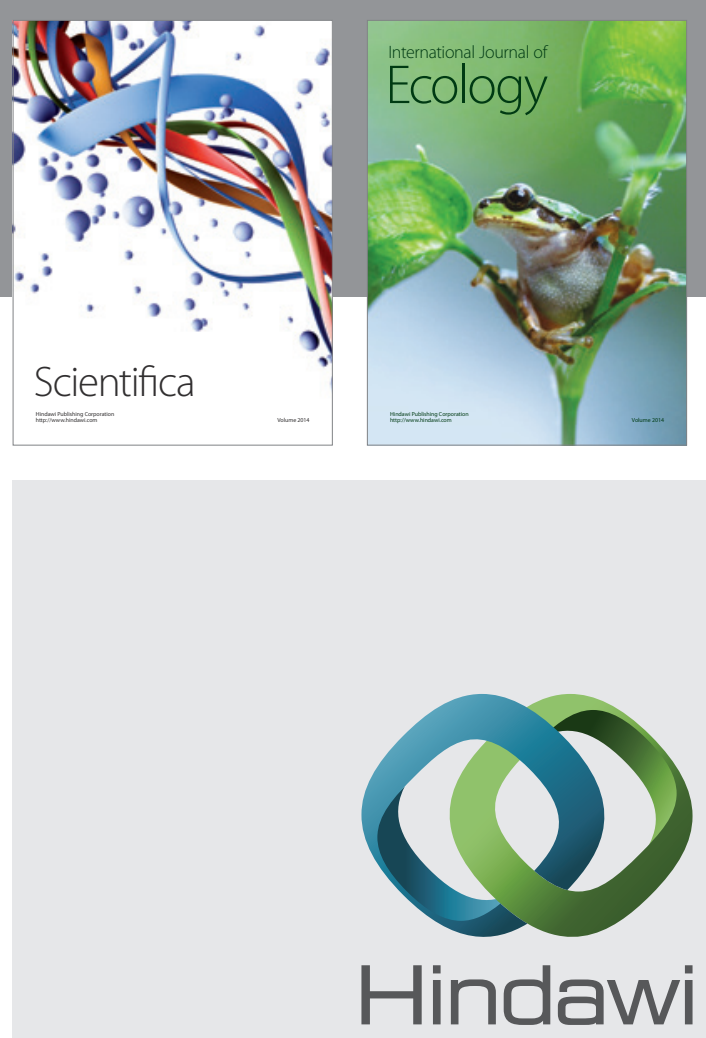

Submit your manuscripts at

https://www.hindawi.com
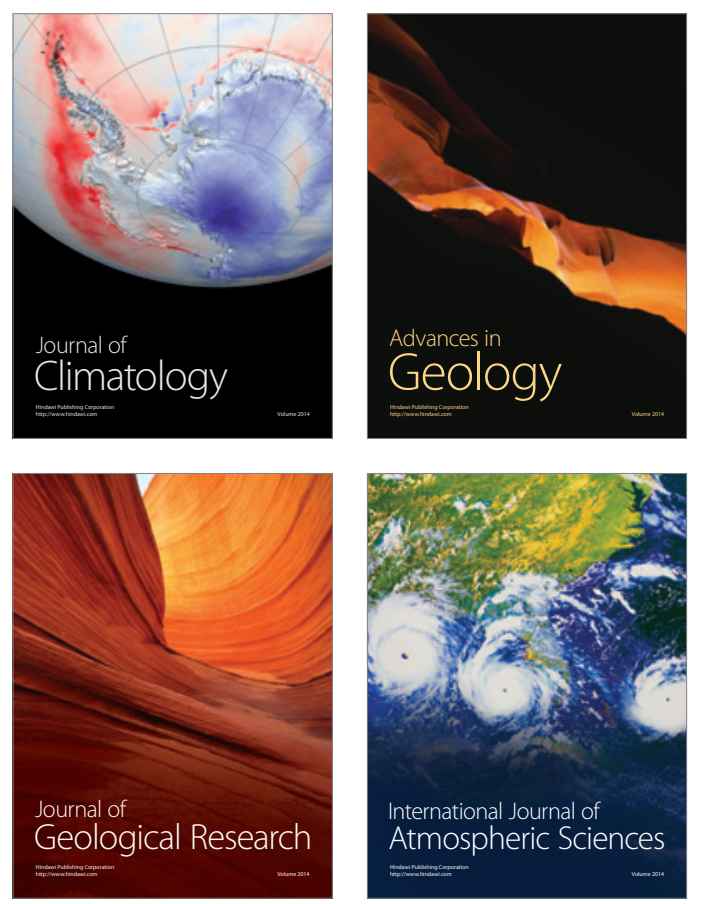

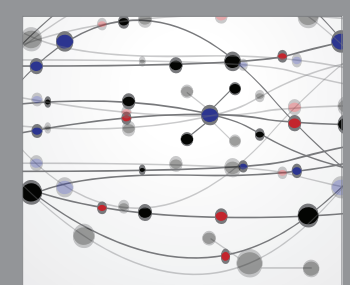

The Scientific

\section{World Journal}
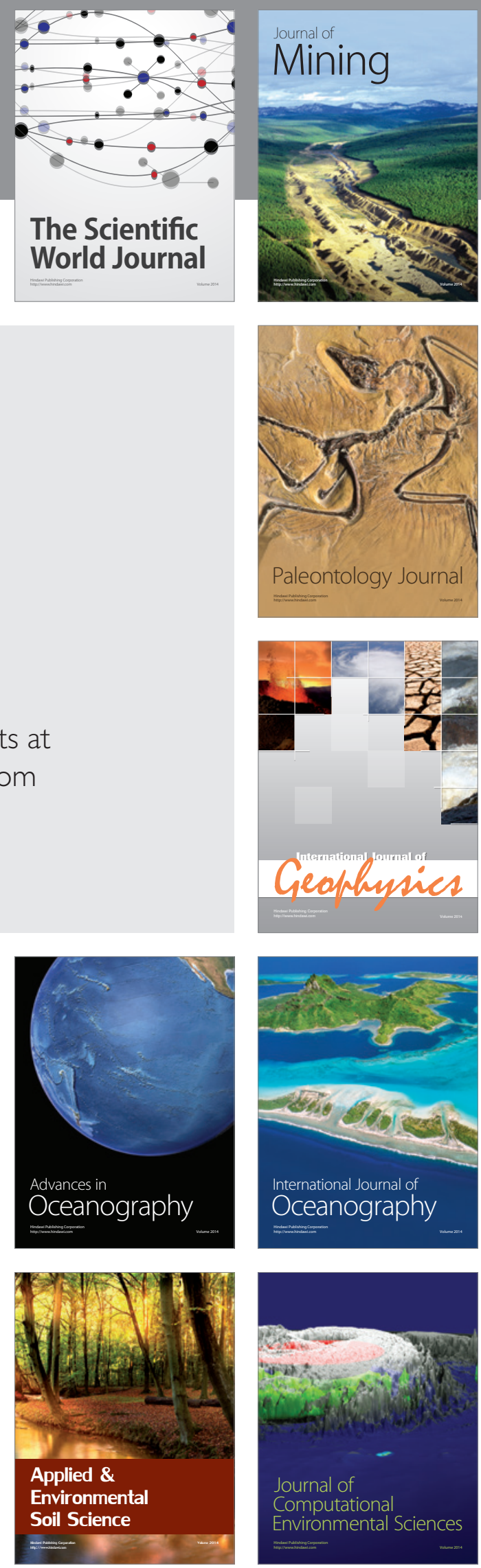